\title{
ANÁlISE ADMINISTRATIVA SOBRE ADEQUAÇÃO DE ÁREA FÍSICA *
}

\author{
Anamaria Carneiro ** \\ Luiza Muniz da Costa Vargens ***
}

ReBEn/04

CARNEIRO, A. e Colaboradora - Análise Administrativa sobre Adequaçāo da Area Físíca. Rev. Bras. Enf.; DF, 34 : 243-259, 1981.

\section{RESUMO:}

O papel do enfermeiro nas instituições hospitalares, como tema de dissões e trabalhos, vem sendo abordado sob vários aspectos, entre eles o de administrador.

Como administrador, o enfermeiro deve estar familiarizado com métodos e técnicas de organização e reorganização de empresas que prestam serviços à população.

A busca destas informações evidenciou como base do processo a análise administrativa, objeto deste estudo, limitado pelo objetivo:

- identificar elementos logísticos de enfermagem em uma unidade hospitalar, que possam constituir subsídios para a organização de unidades simila- res, notadamente no que se refere ao ambiente físico.

Concluimos que a análise administrativa:

- pode ser operacionalizada parceladamente;

- necessita conhecimento e motivação para aplicação na prática de enfermagem;

- a planta física estudada, constitui subsídios para organização de unidades similares.

\section{INTRODUÇÃO}

O papel do enfermeiro nas instituiçōes hospitalares, como tema de discussões e trabalhos, vem sendo abordado sob vários aspectos. Entre eles o de

* Pesquisa descritiva realizada, visando ao processo ensino-aprendizagem na disciplina Logística do Serviço de Enfermagem, ministrada pela Prof. ${ }^{a}$ Nalva Pereira Caldas no 2..$^{\circ}$ período letivo de 1980.

* Auxiliar de Ensino do Departamento de Enfermagem Médico-Cirúrgica - Escola de Enfermagem Alfredo Pinto - UNIRIO. Aluna do Curso de Mestrado em Enfermagem - UFRJ.

*** Aluna do Curso de Mestrado em Enfermagem da UFRJ. 
CARNEIRO, A. e Colaboradora - Análise Acministrativa sobre Adequaçāo da Área Físíca. Rev. Bras. Enf.; DF, 34 : 243-259, 1981.

administrador é enfatizado por uns e mencionados por outros.

Como administrador, o enfermeiro deve estar familiarizado com os métodos e técnicas de organização e reorganização de empresas que prestam serviços à população.

A busca de informações sobre práticas de organização e reorganização evidenciou como base do processo a ANÁLISE ADMINISTRATIVA, que constitui o objeto deste estudo.

A linha de trabalho foi delimitada a partir dos objetivos, assim definidos:

- Realizar atividade didática, visando ao processo ensino-aprendizagem na disciplina logística do Serviço de Enfermagem.

- Identificar elementos logísticos de enfermagem em uma unidade hospitalar, que possam constituir subsídios para a organização de unidades similares, notaciamente no que referem ao ambiente śísico.

Toda c qualquer empresa tem como objetivo máximo a eficiência e eficácia de suas atividades.

As instituições hospitalares, sejam de pequeno, médio ou grande porte, constituem empresas que prestam serviço especializado à comunidade. Sendo sua especialidade promover a saúde, necessita preocupar-se com a eficácia de suas atividades para que a comunidade servida pela empresa mantenha um bom nível de saúde e conseqüentemente maior força de trabalho. A eficiência também merece atenção, para que a instituição possa obter recursos que permitam atender à demanda de serviços c/ou aferir lucros em caso de empresa privada.

A aplicação de técnicas e métodos de organização possibilitará o sucesso do empreendimento. A análise administrativa como primeira fase é o alicerce para um planejamento e implantação bem sucedida, assim como é uma fase impres- cindível para avaliação e reorganização do trabalho.

CANTANHEDE (1) denomina esta primeira fase de levantamento e assim a define: "Consiste o levantamento em um inquérito, em um cadastramento das informações e dos dados coletados e em uma análise crítica dos mesmos."

Para MIRANDA (5): "O levantamento é o estudo das condições estruturais físicas, operacionais, financeiras e materiais da entidade." e "Análise é a crítica, a apreciação dos elementos colhidos."

A análise administrativa tem, portanto, como fim fazer um diagnóstico da situação e estudar elementos chaves na organização e reorganização de uma empresa. Esses elementos estão contidos nas respostas às perguntas que se seguem:

Por que se faz o trabalho?

Que é feito?

Quem faz o trabalho?

Como ele é feito?

Onde se o faz?

Quando ele é feito? 1, 5

Pode-se perceber a complexidade e amplitude da análise administrativa, através da classificação encontrada na obra de RONCHI (6) que subdivide em três tipos de estudo.

- Análise funcional: o estudo das atividades de uma empresa.

- Análise estrutural: é o estudo que procura identifcar os grupos de individuos opurantes e as recíprocas relaçōes significativas na estrutura da empresa.

-- Análise dos métodos de trabalho: preocupa-se em estudar as várias atividades que são desenvolvidas em relação às condiçōes do ambiente e dos meios físicos pelos quais o trabalho se realiza. 
CÁRNEIRO, A. e Colaboradora - Análise Administrativa sobre Adequaçāo da f́rea Físíca. Rev. Bras. Enf.; DF, 34 : 243-259, 1981.

Classificação semelhante e feita por GLASER (*) ao dividir o levantamento em três fases:

1. ${ }^{\mathrm{a}}$ análise por função

2. análise da estrutura

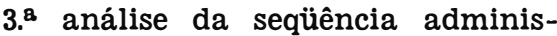
trativa.

Discorrendo a seguir sobre os pontos a serem abordados em cada uma das fases mencionadas.

Essa sintese do assunto evidencia que a análise administrativa de uma empresa exige tempo e conhecimentos não só de administração como também do campo onde será desenvolvida.

Este trabalho, portanto, propõe-se a uma tentativa de analisar um dos aspectos de uma unidade hospitalar, a PLANTA FISICA.

Para melhor compreensão da planta física tornou-se necessário caracterizarse a unidade através de sua identificação, dimensionamento e localização estrutural.

\section{REVISÃO DE LITERATURA}

No processo saúde-doença, a unidade de internação cirúrgica tem um papel relevante na recuperação da saúde.

Da boa organização da unidade de internação, depende sua significância no complexo hospitalar propiciando a este atingir sua principal meta: a reintegração do cliente à comunidade.

Um dos elementos fundamentais para a manutenção de um processo organizacional eficiente e eficaz, é a análise de situações administrativas, com base em experiências diversificadas registradas na literatura.

\section{1 - Planta Física:}

O homem interage com o meio ambiente no qual se encontra, resultando desta interação equilíbrio ou desequil:brio que se refletirá no homem como um todo.

$\mathrm{Na}$ busca deste equilíbrio, a planta física vem-se destacando por exercer papel preponderante na constituição do ambiente terapêutico.

Tal é a sua importância para o sucesso desta terapêtica e para facilitação das atividades nos serviços de saúde que, para as entidades governamentais brasileiras, vem sendo objeto de estudo.

Deste estudo resultou a elaboraçāo de normas e padrões de construções e instalações de serviços de saúde (7), cuja observância tornou-se obrigatória em todo território nacional, através das Portarias do Ministério da Saúde n. ${ }^{\circ} 400$ de 6/12/77 e n. ${ }^{\circ} 138$ Bs B, de 27/3/78.

Os critérios estabelecidos para esta normatização consideram o porte das instituições de saúde e os serviços a serem prestados.

No referido documento, são indicados padrões quanto as características, destinação, metragem de área mínima dos componentes da planta física, abrangendo os seguintes itens: elementos, circulação, acabamento, destino final dos dejetos e técnicas sobre instalações.

\subsection{1 - Elementos:}

Ao tratar da unidade de internação, enumera como seus elementos: Posto de Enfermagem; Sala de Serviço; Sala de Exame e Curativos; Sala de Utilidades; Depósito de Material Sujo; Copa; Sala para Refeitório ou de Estar; Rouparia; Depósito de Materiais e Equipamentos; Sanitário para Pessoal; Sala para Relatório e Prescrição Médica; Quarto de Isolamento; Sanitário Anexo ao Quarto de Isolamento; Anticâmara com Lavatório e Visor; Quarto para um leito, Sanitário anexo ao quarto de um leito;

(*) Apud MIRANDA (5). 
CARNEIRO, A. e Colaboradora - Análise Administrativa sobre Adequação da Area Físíca. Rev. Bras. Enf.; DF, 34 : 243-259, 1981.

Quarto para dois leitos; Sanitário anexo ao quarto de dois leitos; Enfermaria para 3 leitos; Sanitário anexo à Enfermaria de 3 leitos ou mais. Acresce a essa relação as respectivas metragens de área, tecendo consideraçōes quanto às suas características e destinação.

\subsection{2 - Circulação:}

As normas sobre circulação traçam padrões generalizáveis a todo o hospital quanto à circulação horizontal (ccrredores) e a circulação vertical (escadas, rampas, elevadores, monta cargas).

Faz especificações quanto à largura mínima, destinação e a aspectos críticos do tráfego, quanto a informaçōes adicionais relativas a escadas, rampas, elevadores e monta cargas.

\subsection{3 - Acabamento:}

As disposiçōes sobre o acabamento abrangem todo o hospital, assim como sobre tetos, paredes, pisos, esquadrias, metragens de pé direito e modulação.

As disposiçōts pertinentes à unidade referem-se:

a) a resistência, facilidade de limpeza, manutenção e substituição de canos, cuidados quanto à radiação e a fontes de ruído ou vibração dos tetos, paredes e pisos;

b) as dimensões e medidas de segurança das esquadrias salientando as indicaçōes do uso de trincos, grades, telas e vidros.

\subsection{4 - Instalações para o destino adequado e final dos de- jetos:}

O documento remonta à norma $\mathrm{N}$ B-19 da ABNT, a qual soma especificações, tais como:

- localização dos tubos de esgoto e ralos

(*) Apud LólA (4).
- fluxo e direção de escoamento

- qualidade do material dos tubos

- tratamento e destino dos dejetos visando à proteção do meio ambiente.

\subsection{5 - Normas técnicas sobre ins- talações:}

Discorrendo sobre aspectos técnicos de instalações sanitárias, elétricas, hidráulicas e as de proteção e combate a incêndio, são fornecidos esclarecimentos visando:

a) a assegurar, através da estrutura física, a integridade da clientela;

b) à prevenção de infecçōes e contaminações;

c) à adequação e eficácia do funcionamento geral das instalações do hospital, assim como a obtenção da durabilidade máxima das mesmas.

\subsection{6 - Apreciação sobre o ambi- ente:}

Outros fatores, além da disposição da planta física, são determinantes do ambiente. Entre eles, condições atmosféricas, iluminação, som, estética.

\section{- Condições atmosféricas:}

Os estudos desenvolvidos sobre este fator são unânimes em evidenciar a sua importância para um ambiente terapêtico. No entanto, divergem no que se refere a particularidades.

Assim, para PRICE (*) a temperatura ambiente de $20^{\circ} \mathrm{C}$ pode ser a melhor adaptada para a maioria das pessoas, e temperaturas acima de $27^{\circ} \mathrm{C}$ podem produzir a sensação de calor excessivo e conseqüentemente altera a energia natural, secreção sudorípara e sensibilidade ao frio. Já para BE- 
CARNEIRO, A. e Colaboradora - Análise Administrativa sobre Adequação da Area Físíca. Rev. Bras. Enf.; DF, 34 : 243-259, 1981.

LAND (*), a temperatura essencial para o conforto é em torno de $21^{\circ} \mathrm{C}$ e CULVER (*) diz que esta temperatura não obstaculiza as funções normais.

Referindo-se à Umidade, DUGAs (2) considera que a Umidade de $40 \%$ a $60 \%$ é a mais indicada para hospitais, e justifica que valores mais altos reduzem a evaporação da transpiração predispondo ao cansaço e intensificando as sensações de frio e calor. Relaciona, ainda, o baixo grau de umidade à necessidade de temperautra ambiente mais elevada.

Quanto ao movimento do ar e ventilação, as abordagens encontradas dizem respeito ao fato de poderem ser naturais ou artificiais, relacionadas às dimensões do espaço físico e da importância de se evitar correntes de ar.

- Iluminação:

Os serviços de saúde utilizam iluminação artificial e natural.

FUERST (3) define uma boa iluminação como aquela que permite às pessoas enxergarem claramente e sem esforço a tarefa que estão fazendo ou campo visado. Diz ainda que não deve ser ofuscante e deve produzir um minimo de sombra.

Os aspectos de uma boa iluminação destacados por LóLA (4) mencionam a luz natural como a mais econômica, a que possui propriedades curativas (aumenta a resistência às enfermidades $\mathrm{e}$ contribui para a terapia), a que possui propriedade de aquecimento e de estímulo para as faculdades mentais. $\mathbf{E}$ quanto à iluminação artificial, a necessidade de se manter o efeito estimulante do contraste e o perigo do incômodo e deslumbramento. Referindo-se à utilização dessa iluminação, sugere, para durante a noite, uma luz difusa situada ao nivel do solo para que facilite ao cliente usar os serviços higiênicos sem que a luz o impeça de voltar a dormir com facilidade. Cita o excesso de iluminação como capaz de produzir irritabilidade e dano ao organismo do cliente.

- Som:

Os mais diversos ruídos são produzidos em uma unidade de internação em decorrência da movimentação de pessoal e material.

Desses ruídos podem surgir desconfortos e para minimizá-los DUGAS (2) sugere o emprego de materiais especiais em paredes, pisos e tetos, bem como a substituição de utensilios de aço inoxidável, pelos de plástico.

A influência do som no organismo humano é vista por LÓLA (4) como: "ausência pode levar o individuo à monotonia e ao tédio; e o ruído forte que pode ser danoso a uma pessoa hospitalizada causando desconforto e irritação".

“... o uso da música ambiente é bem apreciada por grande quantidade de pessoas".

\section{- Estética:}

Segundo CULVER (*), "a estética envolve todos os objetos ou complementos que servem de atrativo e estimulam o cliente e compreende: disposição e ordem que são fatores que asseguram o efeito harmonioso". Ressalta ainda como pontos fundamentais a serem atendidos no ambiente: o equilíbrio, simetria e cor.

Para LOLA (4): "No ambiente, as tonalidades claras quebram a monotonia do ambiente e podem ser usadas nas paredes, no mobiliário, nas colchas de cama e cortinas. As ações das cores mais relevantes e que permitem melhor comodidade à visão são: calmante (azul); sedantes (cinza-azulado e lavanda cinza); sensação de incômodo (roxa); des-

(*) Apud IOOLA (4) 
CARNEIRO, A. e Colaboradora - Análise Administrativa sobre Adequação da Area Fisíca. Rev. Bras. Enf.; DF, 34 : 243-259, 1981.

perta o interesse (pastel e outras tonalidades claras).

- Mobiliário:

O mobiliário é uma das variáveis que influencia o ajustamento do cliente ao ambiente.

Dentre as peças de mobiliário enumeradas por LÓLA (4), destacaram-se as seguintes:

- Colchão - deve ser firme para conservar o corpo em alinhamento correto e cobertos com material plástico para protegêlos e facilitar a limpeza.

- Mesa de cabeceira - é usada para guardar os pertences do cliente e deve ser mais alta que o nivel lateral da cama para que este possa alcançar sua superficie superior comodamente.

- Biombos - é empregado com várias finalidades, principalmente a de assegurar a privacidade do cliente.

Os móveis devem reunir certas qualidades, como serem providos de rodas que girem facilmente e sem ruídos de m:odo a facilitarem o transporte; serem fáceis de limpar, possuirem superfícies sólidas e duradouras, que possam resistir à limpeza e ao uso prolongado (anexo 2).

\section{MATERIAL E METODOS}

Selecionou-se para campo de investiganão um hospital universitário, por constituir a instituição mais recentemente implantada no Rio de Janeiro, onde são desenvolvidas práticas de ensino de enfermagem pela instituição, onde as autoras cursam o mestrado.

Para o levantamento de dados, visando ao diagnóstico da situação admi- nistrativa, recorreu-se aos seguintes métodos:

a) Entrevistas: foram realizadas seis entrevistas, duas com a assessora da Diretora da Divisão de Enfermagem; uma com a Chefe do Serviço de Enfermagem de Internações Cirúrgicas; uma com o Chefe de Setor; uma com o Diretor da Divisão de Engenharia e uma com o Chefe de Serviço de Manutenção e Operações;

b) Observação direta: sobre os aspectos da estrutura administrativa e da planta física;

c) Análise de documentos: para obtenção de dados fora consultados os registros estatísticos do Departamento de Pessoal do hospital, Regimento, Normas e Inventário do material e instalação do Setor 10-B.

Na realização deste estudo, procedeu-se a levantamento bibliográfico, visando estabelecer um referencial teórico, objetivando a análise critica dos dados colhidos sobre planta física.

Compararam-se os achados aos padrões referidos na literatura, preponderantemente às normas propostas pelo Ministério da saúde de 1979.

Foram integralmente anexadas ao trabalho, exclusivamente, as que versam sobre planta física.

Discutiram-se as inferências desta comparação à luz dos princípios logísti$\cos$ de enfermagem.

\section{RESULTADOS}

As normas e padrões estabelecidos pelo governo consideram o porte do hospital ao dimensionar a planta física para que esta se torne funcional.

Faz-se portanto necessário caracterizar a unidade em estudo, para que se proceda à análise administrativa da 
CARNEIRO, A. e Colaboradora - Análise Administrativa sobre Adequaçāo da Area Físíca. Rev. Bras. Enf.; DF, 34 : 243-259, 1981.

adequação do espaço físico ocupado, assim sendo serão apresentados dados sobre movimentação de pacientes, a estrutura organizacional e a lotação de pessoal.

\section{1 - Caracterização da unidade}

\subsection{1 - Identificação:}

A unidade estudada destina-se a receber clientela de cirurgia cardiovascular torácica. Recebe ainda, ocasionalmente, clientes de outras clínicas cirúrgicas conforme disponibilidade de leitos ociosos.
No período estudado, a referida unidade ocupou duas áreas físicas diferentes, a saber: localizada até maio no setor $10 \mathrm{C}$ e a partir de junho no setor $10 \mathrm{~B}$.

Segundo a chefia do setor, a mudança visou a reajustar o número de leitos à demanda especializada.

\subsection{2 - Dimensionamento}

$$
\text { 4.1.2.1 - Lotação }
$$

\begin{tabular}{cc}
\hline MAIO & JUNHO \\
\hline 34 & 30 \\
\hline
\end{tabular}

4.1.2.2 - Movimento da Unidade - Maio/Junho/1980

\begin{tabular}{|c|c|c|c|c|}
\hline \multirow[b]{2}{*}{ ESPECIFICAÇÃO } & \multicolumn{2}{|c|}{ MAIO } & \multicolumn{2}{|c|}{ JUNHO } \\
\hline & $\begin{array}{l}\text { SETOR } \\
10 \mathrm{C}\end{array}$ & H.U. & $\begin{array}{l}\text { SETOR } \\
10 \mathrm{~B}\end{array}$ & H.U. \\
\hline № de internações & 55 & 677 & 40 & 730 \\
\hline № de pacientes saídos & 53 & 723 & 39 & 662 \\
\hline Altas & 50 & 689 & 38 & 627 \\
\hline óbitos & 03 & 34 & 01 & 35 \\
\hline № de leitos & 34 & 447 & 30 & 447 \\
\hline № de leitos/dia & 1054 & 1.3857 & 900 & 13410 \\
\hline № de pacientes/dia & 719 & 10275 & 692 & 10539 \\
\hline Porcentagem de ocupação & $68 \%$ & 74 & 77 & 79 \\
\hline Tempo médio de permanência & 14 & 14 & 18 & 16 \\
\hline Média de paciente/dia & 23 & 331 & 23 & 351 \\
\hline № de pacientes removidos & - & 07 & 01 & 11 \\
\hline
\end{tabular}


CARNEIRO, A. e Colaboradora - Análise Administrativa sobre Adequaçāo da Area Físíca. Rev. Bras. Enf.; DF, 34 : 243-259, 1981.

4.1 .3 - Localização estrutural da unidade de internação:

\subsubsection{1 - Organograma do hospital universitário estudado}

A unidade de internação, foco deste estudo, como as demais, é a maior parcela no âmbito da estrutura organizacional das divisões de serviços assistenciais, que são:
— Divisão de Enfermagem

- Divisão Médica

- Divisão de Apoio Assistencial e

— Divisão de Saúde da Comunidade.

Essas divisões situam-se no mesmo nivel estrutural e possuem a mesma linha de autoridade e comando em relação à direção do hospital universitário.

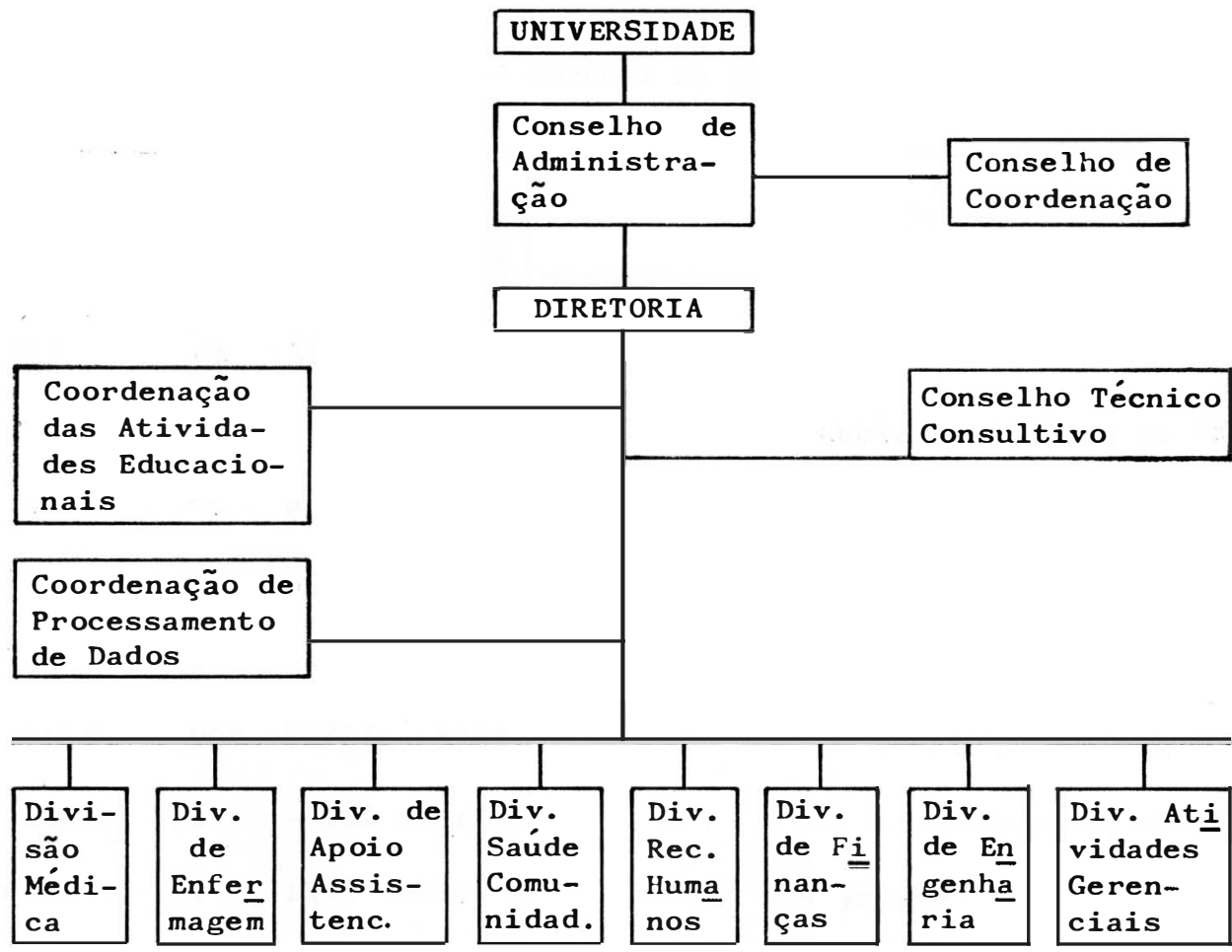

4.1.3.2 - Situação da unidade de internação cirúrgica na estrutura da Divisão de Enfermagem
A Divisão de Enfermagem conta com seis Serviços do mesmo nível, porém de porte diverso.

Organograma do Serviço de Internação Cirúrgica, em seguida apresenta- 
CARNEIRO, A. e Colaboradora - Análise Administrativa sobre Adequação da Area Físíca. Rev. Bras. Enf.; DF, 34 : 243-259, 1981.

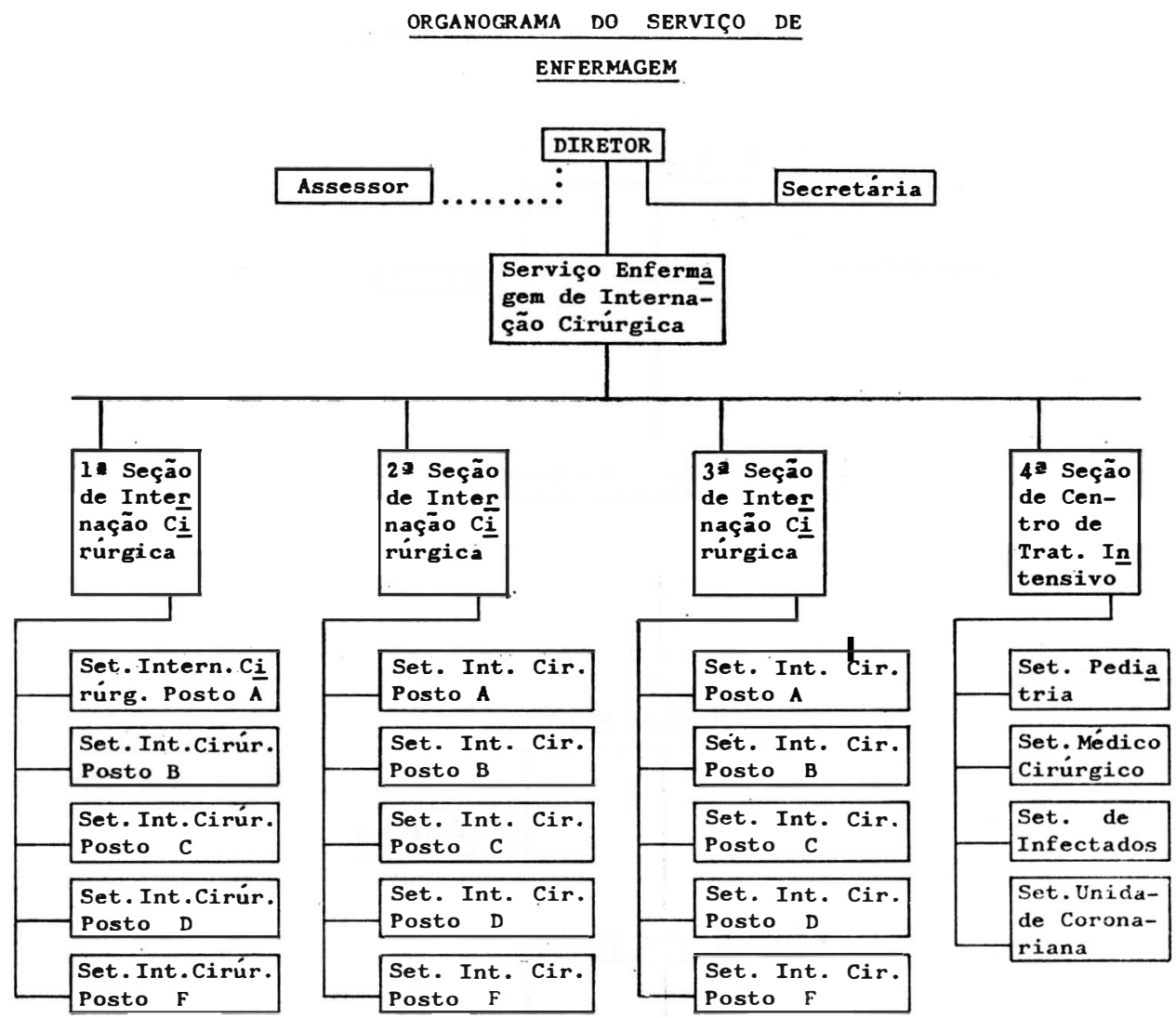

do, identifica-se a situação do setor em estudo.

\subsubsection{3 - Hierarquia funcional da Di- visão de Enfermagem no hos- pital universitário estudado}

O pessoal de enfermagem observa, no hospital universitário estudado, a hierarquia funcional apresentada (vide pág. 252) :

Segundo essa hierarquia, estavam lotados no Setor $10 \mathrm{~B}$ as seguintes categorias funcionais, assim distribuidas por turno (vide pág. 253):

\section{2 - Planta Física:}

Observação da planta física incidiu sobre o seguinte: elementos constituin- tes, área de circulação, acabamento, instalações para o destino final dos dejetos, instalações elétricas, hidráulicas, sanitárias e para combate de incêndio; bem como observações sobre o ambiente.

$\mathrm{Na}$ descrição dos elementos que constituem a planta física procurar-se-á oferecer a idéia da ocupação do espaço incluindo referências sobre instalações, mobiliário e pessoal.

\subsection{1 - Elementos:}

\subsubsection{1 - Posto de enfermagem:}

A área do posto de enfermagem é de $10 \mathrm{~m}^{2}$ possuindo em anexo uma sala para o Chefe do Setor com $12 \mathrm{~m}^{2}$ e uma área para prescrição médica e relatórios com $7,5 \mathrm{~m}^{2}$. 
CARNEIRO, A. e Colaboradora - Análise Administrativa sobre Adequaçāo da Area Físíca. Rev. Bras. Enf.; DF, 34 : 243-259, 1981.

\section{HIERARQUIA FUNCIONAL DA DIVISĀO DE ENFERMAGEM DO HOSPITAL UNIVERSITARIO ESTUDADO}
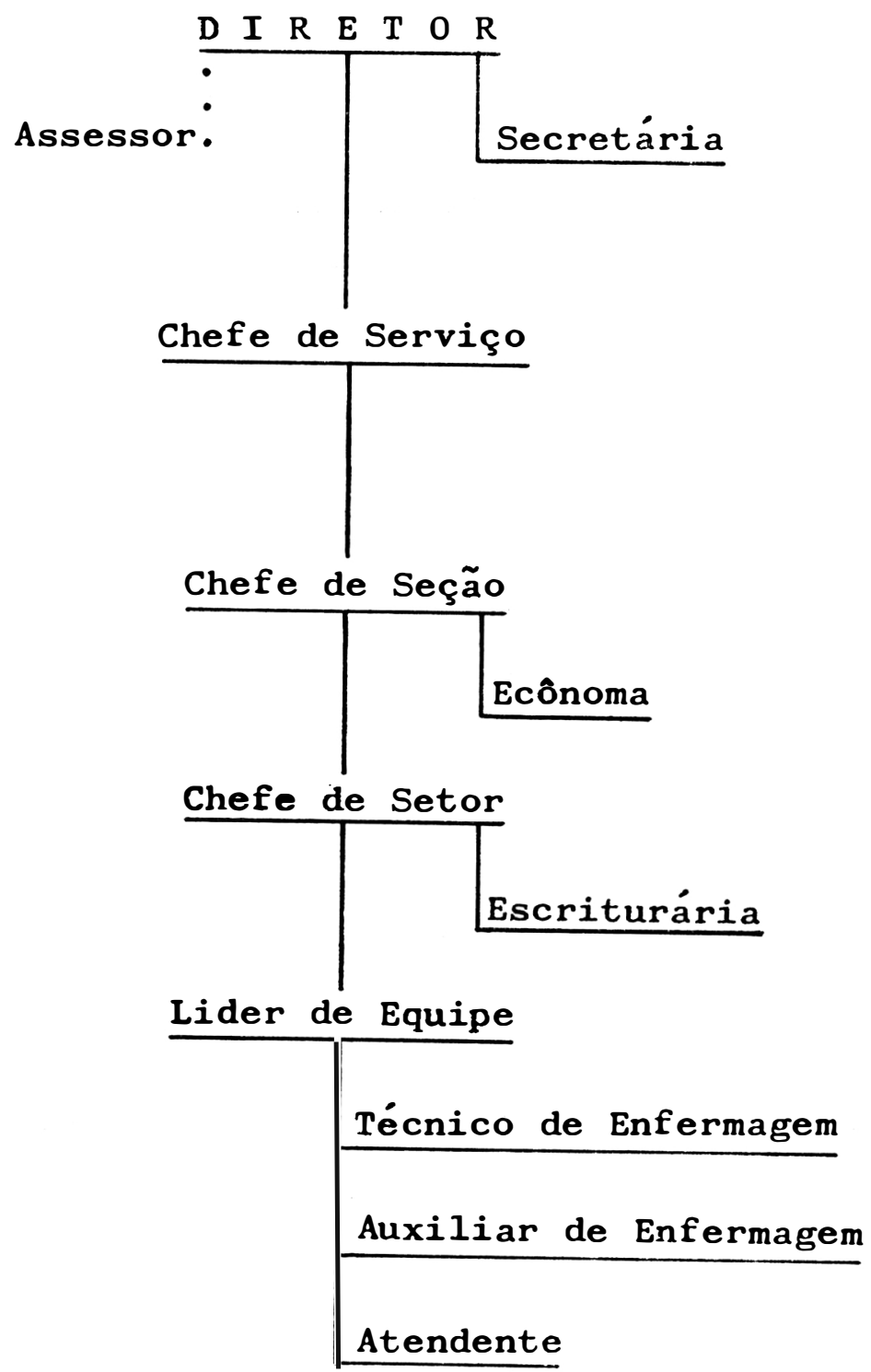

Está separada do corredor por um balcão que possibilita ao pessoal em serviço controlar o movimento de entrada na unidade, sobre o mesmo estão loca- lizados os telefones e material de serviços burocráticos servindo de mesa de trabalho para a secretária do Serviço de Enfermagem. As instalaçōes incluem: 
CARNEIRO, A. e Colaboradora - Análise Administrativa sobre Adequaçāo Area F1síca. Rev. Bras. Enf.; DF, 34 : 243-259, 1981.

\begin{tabular}{|c|c|c|c|c|}
\hline CATEGORIA & MANHA & TARDE & NOITE & TOTAL \\
\hline Enfermeiro & 2 & 2 & 1 & 5 \\
\hline Técnico de Enfermagem & 2 & 1 & 1 & 4 \\
\hline Auxiliar de Enfermagem & 5 & 4 & 2 & 11 \\
\hline Atendente & 2 & 1 & 1 & 4 \\
\hline TOTAIS & 11 & 8 & 5 & 24 \\
\hline
\end{tabular}

O balcão, constituido por armários e gavetas onde são guardados os excessos de prontuários e material de escritório; ainda no posto de enfermagem, lateralmente ao balcão e de fácil acesso encontra-se um armário subdividido em vários compartimentos onde são guardados os impressos utilizados no hospital.

A sala do Chefe do Setor é destinada à passagem de plantão, desempenho de algumas atividades burocráticas e administrativas. Nesta sala, guardam-se a medicação controlada em cofre, pastas de normas do serviço de enfermagem, rotinas, tombamento de material, fichário para arquivo de registros.

A área destinada à prescrição e a relatório possui instalação de balcões ao longo da parede e cadeiras giratórias.

Os prontuários são guardados em uma pequena estante com rodas para possibilitar o deslocamento entre as áreas citadas acima.

\subsubsection{2 - Sala de serviço:}

Anexa ao posto de enfermagem está a sala de serviço que possui de área $20 \mathrm{~m}^{2}$. O mobiliário é constituído de 1 geladeira, 1 carro de medicação com gavetas, em números correspondentes aos das enfermeiras e subdivididas em compartimentos correspondentes aos leitos. O Serviço de Farmácia possui réplica destas gavetas. Nelas são diariamente depositadas os medicamentos em invólucros rotulados, para uso de cada cliente durante 24 horas.

As gavetas da enfermaria são diariamente substituídas pelas réplicas montadas na Farmácia.

Existe 1 armário - balcão, com prateleiras e gavetas voltadas para a sala de serviço e servindo simultaneamente para separá-la do Posto de Enfermagem, é utilizado principalmente para guarda de materiais esterilizados.

O outro armário é localizado acima da pia, com prateleiras e portas onde são mantidos utensilios e equipamentos para tratamento de enfermagem.

Sob a pia encontra-se outro armário, que é utilizado para a guarda de solutos empregados na terapêutica, possuindo gavetas, prateleiras e portas.

Todo o mobiliário é revestido de fórmica branca. A pia é em aço inoxidável, possuindo duas bacias e um balcão, torneiras de água quente e fria paia cada bojo. 
CARNEIRO, A. e Colaboradora - Análise Administrativa sobre Adequação da Area Fisíca. Rev. Bras. Enf.; DF, 34 : 243-259, 1981.

\subsubsection{3 - Sala de exames e cura- tivos:}

Sua dimensão é de $15 \mathrm{~m}^{2}$, nesta área encontram-se instalados um balcão com uma pia sob o qual três armários com prateleiras e portas e 5 gavetas. Uma mesa articulada para exames. Um carro de curativo, uma mesa auxiliar com tampo e prateleiras inoxidáveis e rodas.

Usada para exame e tratamento de clientes internados.

\subsubsection{4 - Sala de utilidades:}

Area aproximada de $10,80 \mathrm{~m}^{2}$, destinada à limpeza, desinfecção e guarda de utensilios sanitários usados no atendimento de clientes. São utilizados para limpeza e desinfecção uma lavadora de comadre, um tanque e uma pia. Na parede oposta a essas instalações, existe um balcão com armárío para guarda de material. A roupa usada na unidade é guardada na sala de utilidades em hamper duplo de lona e tampo. Ficam estacionados nesta área um carro para transporte de material e um carro e um carro para limpeza, ambos de aço inexidável.

\subsubsection{5 - Copa:}

A copa inclui área destinada à distribuição de alímentos com dímensão de $13,6 \mathrm{~m}^{2}$ sendo anexa ao refeitório, possuindo pia, balcão e fogão. Serve aos quatro setores do andar.

\subsubsection{6 - Refeitório:}

Área aproximada de $73,24 \mathrm{~m}^{2}$, serve aos quatro setores do andar, possui mesas e cadeiras.

\subsubsection{7 - Sala de estar:}

A sala de estar ou recreação está localizada no hall dos elevadores, delimitada por uma mureta que serve de es- paldar para os sofás ao longo de três lados. Tem uma mesa de centro com revistas e um televisor preso por suporte à parede. A área é de $68,4 \mathrm{~m}^{2}$, destinando-se à recreação e recepção de visítas dos clientes dos quatro setores do andar.

\subsubsection{8 - Rouparia:}

A rouparia está situada no corredor em frente ao posto de enfermagem, possui uma área de $4 \mathrm{~m}^{2}$ com prateleiras que ocupam a extensão das 3 paredes. E destinada à guarda de roupa limpa a ser usada na Unidade.

\subsubsection{8 - Sala de material:}

Localizada no corredor em frente à sala de utilidades, com área de $4,81 \mathrm{~m}^{2}$, destina-se à armazenagem de material de limpeza.

\subsubsection{0 - Sala de equipamentos:}

Possui área de $4,60 \mathrm{~m}^{2}$, localizandose ao lado da rouparia. Nela são guardadas macas, cadeiras de roda, suportes para soro, focos portáteis e vários equipamentos.

\subsubsection{1 - Sanitários para pessoal:}

Anexo à sala de utilidades existe um banheiro com área de $1,80 \mathrm{~m}^{2}$, utilizado exclusivamente pelo pessoal do setor de ambos os sexos. Existe no andar outro banheiro com área de $7 \mathrm{~m}^{2}$, provido de boxe com chuveiro, anexo à sala de estar multiprofissional, que serve ao pessoal dos 4 setores.

4.2.1.12 - Quarto para dois leitos:

O setor dispõe de dois quartos com capacidade para dois leitos, ambos com as mesmas dimensões, isto é, área de $14 \mathrm{~m}^{2}$, com 1 sanitário com chuveiro de $3,6 \mathrm{~m}^{2}$ de área para cada quarto. 
CARNEIRO, A. e Colaboradora - Análise Administrativa sobre Adequaçāo da Area Fisíca. Rev. Bras. Enf.; DF, 34 : 243-259, 1981.

\subsubsection{3 - Enfermaria para se is leitos:}

Existem no setor quatro enfermarias idênticas ao longo do corredor do lado contrário ao Posto de Enfermagem, com metragem de $54,52 \mathrm{~m}^{2}$ possuindo em anexo um sanitário com um chuveiro ocupando área com $7 \mathrm{~m}^{2}$.

\subsubsection{4 - Elementos comuns}

Além dos elementos comuns para o uso da clientela do andar (copa, refeitório e sala de recreação) existem outros comuns aos quatro setores do andar, destinados ao desempenho específico dos profissionais de Serviço Social e de Nutrição.

A existência de local próprio na planta física, para os líderes do Serviço Social e de Nutrição, assim como para os chefes de enfermagem em todos os níveis, reflete a estrutura organizacional e o status da Divisão de Enfermagem.

\subsection{2 - Instalaçōes:}

\subsubsection{1 - Hidráulicas:}

As instalações hidráulicas subdividem-se em ductos de água quente e fria e de esgoto. A canalização é de ferro, sendo o diâmetro da tubulação destinada ao esgoto maior do que a de água. As tubulações são dispostas horizontalmente entre os andares, percorrendo faixas laterais sobre o teto do corredor. São redistribuídas para os elementos do setor através de quatro "shafts" verticais, o acesso a estas instalações para manutenção é feito através dos "shafts" cujas portas estão no corredor.

As torneiras são de aço inoxidável, com sinalização de quente e frio.

Neste setor, existem ralos nas salas de serviços, utilidades, exames e sanitários.
A rede para despejo de dejetos inicia-se no setor, pelos sifões das pias, ralos e vasos sanitários, sendo drenados por tubulação de efluente para o "shafts" e seguindo para coletores gerais do hospital.

\subsubsection{2 - Elétricas:}

Nos corredores existem painéis de distribuição de energia elétrica com circuitos identificados. São protegidos por portas que facilitam o acesso para manutenção. Existem interruptores, tomadas de 110 e 220 v. algumas das quais, especificas para aparelhos que necessitam amperagem maior do que $15 \mathrm{~A}$.

Nas enfermarias existem 6 tomadas de 110 v e 2 de 220 v. Nos quartos de dois leitos a proporção é de 1 tomada de $110 \mathrm{v}$ para cada leito e 1 de $220 \mathrm{v}$ para cada 2 leitos. Os mesmos tipos de tomadas existem nas salas de serviços, utilidades e exames.

A iluminação artificial é proporcionada por lâmpadas fluorescentes, localizadas nos tetos em quantidade diversa, nos diferentes elementos do setor. Também há iluminação artifical difusa, próxima ao rodapé das enfermarias e do corre dor (luz de vigília).

O sistema alimentador tem capacidade de atender a demanda da ativação simultânea de todos os terminais elétricos do setor.

\subsubsection{3 - Combate a incêndio:}

As instalações para o combate ao incêndio compreende 3 tipos de extintores: extintor de água pressurizada que não pode ser usada nos circuitos elétricos, te m efeito de resfriamento e abafamento; extintor de gás carbônico, funciona por abafamento e é utilizado para combater incêndio e $m$ combustiveis líquidos e equipamentos elétricos; extintor de pó químico seco.

"O hospital universitário estudado dispõe de rede de extintor de incêndio 
CARNEIRO, A. e Colaboradora - Análise Administrativa sobre Adequação da Area F1síca. Rev. Bras. Enf.; DF, 34 : 243-259, 1981.

em número suficiente e em localização conveniente para debelar princípios de incêndio em qualquer de suas áreas. Há também uma rede de hidrantes internos permanentemente alimentada por água, alojados em caixa de incêndio com mangueiras, registros e esguichos prontos para uso. (8)

\subsection{3 - Ambiente:}

O pé direito dos elementos do setor possuem $3 \mathrm{~m}$ de altura e as paredes são pintadas com tinta lavável de cor palha.

O piso é de material sintético, cor cinza, de fácil lavagem, antiderrapante.

As janelas em basculhantes rotativos, que permitem a rotação para limpeza, ocupam a extensão de todas as paredes externas do setor e distam $1,5 \mathrm{~m}$ de piso. São dotadas de telas que diminuem ruidos e o calor.

As portas, de $1 \mathrm{~m}$ de largura, são em madeira pintada de branco, com visor e abrem para dentro da enfermaria.

O mobiliário das enfermarias consta de:

a) camas de fowler com cabeceiras de fórmica cor palma, grades e suportes de soro adaptáveis, rodas e freios; colchão anatômico ortopédico revestido de capa plástica.

b) mesa de cabeceira com gaveta e armário inferior com prateleira, revestida de fórmica em cor palma, com rodízios.

c) mesa de refeição reversível em tocador com espelho e cuba de ação inoxidável, altura regulável por manivela, possuindo rodas $\mathrm{e}$ tampo revestido em fórmica cor palma.

d) uma cadeira em fórmica cor palma para cada leito.

e) uma poltrona cor caramelo para cada enfermaria.

f) biombos de 3 faces, em ação inoxidável e lonita, com rodas.

\subsection{4 - Circulação:}

A circulação horizontal é feita por ım corredor central de $2 \mathrm{~m}$ de largura.

Para circulação vertical são utilizadas escadas e elevadores que obedecem a normas técnicas.

\subsection{5 - Observaçōes:}

O periodo, a que correspondem os dados levantados sobre a planta física neste trabalho, refere-se a maio e junho.

A partir de julho, foram feitas no setor $10 \mathrm{~B}$ as seguintes modificações quanto à utilização de espaço físico:

a) Deslocou-se a sala de estar multiprofissional para outra área do andar.

b) No local da sala de estar foi ativada uma enfermaria de sete leitos.

c) Um quarto de dois leitos é atualmente utilizado para isolamento.

d) Na enfermaria mais próxima ao Posto de Enfermagem foi ativada uma unidade intermediária com seis leitos.

\section{COMENTARIO}

A comparação entre as recomendações constantes da revisão de literatura e os resultados obtidos no levantamento de dados sobre unidade de internação, setor $10 \mathrm{~B}$, revelam peculiaridades quanto à dimensão e ao aproveitamento de área; quanto a aspectos relativos à iluminação, ventilação, esté tica, conforto e de funcionalidade e porte.

$\mathrm{Na}$ área física ocupada pela unidade, existem quase todos os elementos propostos no padrão referido pela literatura, deste deferindo no que concerne a:

- o depósito de material sujo não constitui um elemento isolado e sim faz parte da sala de utilidades. Tal disposição reduz a ne- 
CARNEIRO, A. e Colaboradora - Análise Administrativa sobre Adequaçāo da Area Físíca. Rev. Bras. Enf.; DF, 34 : 243-259, 1981.

cessidade de deslocamento, durante as atividades de esvaziamento dos utensílios usados e sua limpeza. Resultando como vantagens economia de tempoesforço, menor disseminação de germes;

- o depósito de material e equipamento é desmembrado em duas salas de $4 \mathrm{~m}^{2}$, estando, portanto, em conformidade no padrão de $8 \mathrm{~m}^{2}$ para uma única sala. A guarda de equipamentos em áreo separada de material facilita seu controle e conservação; bem como a estocagem de material;

- O quarto de isolamento, que apesar de não existir na planta física inicial, pode ser improvisado em um dos quartos de dois leitos. Isto é possivel devido à disponibilidade de área superior ao padrão para isolamento e possuir sanitário anexo;

- a sala para refeitório ou estar, na unidade estudada, constitui elementos independentes, com área superior à prevista, servindo aos quatro setores do andar, oferecendo oportunidade para maior interrelacionamento entre a clientela;

- o aproveitamento da área física. reservando espaços anexos ao posto de enfermagem, sala de serviço, sala de prescrição médica e sala para o Chefe de Setor, permite a especificidade no desempenho, reduzindo os espaços de circulação, facilitando a comunicação e supervisão.

Todos os elementos do setor $10 \mathrm{~B}$ têm área superior à mínima prevista pelo padrão, entretanto sua disposição propicia eficácia da circulação.

O tipo, disposição e tamanho das janelas e portas proporcionam na- turalmente ventilação, aeração, temperatura e iluminação adequada às várias salas do setor, criando um ambiente confortável. Outro recurso de conforto e segurança ambiental é a iluminação artificial difusa que facilita o deslocacamento à noite sem perturbar o sono.

A harmonia das cores, de teto, piso, paredes, mobiliário, roupa de cama resultam um ambiente agradável.

A ocupação do espaço físico no setor $10 \mathrm{~B}$, pelo mobiliário e instalações, é adequada por manter amplas áreas desocupadas.

O número de pessoas circulantes na área é compatível, resultando em bom fluxo.

O organização da unidade de paciente compreendendo mobiliário individual que permite a guarda de objetos pessoais, assim como a utilização de biombos respeita a privacidade do cliente.

A ordem e limpeza das unidades tornam o ambiente acolhedor e sossegado.

Segundo a literatura consultada, os aspectos anteriormente mencionadas são fatores que contribuem para o ajustamento do cliente hospitalizado.

Considerando-se o porte e especialização do setor, expressos estatisticamente no item que caracteriza a unidade em estudo, constata-se a suficiência e funcionalidade da planta física.

\section{CONCLUSŌES}

Na realização deste trabalho, as autoras depararam com uma nova visão sobre análise administrativa e com a possibilidade de operacionalizá-la. par. celadamente. Desta nova visão surge o conhecimento e motivação para a apiicação de análise administrativa, no desempenho de atividades de enfermagem.

Os tipos e ao montante de vantagens identificadas na análise crítica da planta física do hospital universitário 
CARNEIRO, A. e Colaboradora - Análise Administrativa sobre Adequaçāo da Area Físíca. Rev. Bras. Enf.; DF, 34 : 243-259, 1981.

estudado, constitui subsidio relevante para a organização de unidades similares.

\section{SUGESTÕES}

Diante do exposto, as autoras sugerem a realização de estudos, que investiguem a influência de aspectos da planta física, do hospital universitário es- tudado, no ajustamento dos clientes hospitalizados.

Outra linha de pesquisa sugerida é a de identificação de fatores que interferem na relação entre pessoal e planta física.

Sugere-se também que estudos nesta área sejam desenvolvidos em condições que permitam disponibilidade para vivência do campo.

\section{B I B L I O G R A F I A}

1. CANTANHEDE, Cesar - Curso de Organizaçāo do Trabalho. 8. ${ }^{\mathrm{a}}$ ed. Sāo Paulo, Atlas, 1968.

2. DUGAS, de Kozier - Tratado de Enfermeria Prática. 5. ${ }^{a}$ ed. México, Interamericana, 1974.

3. FUERST, Elinor V. et al - Fundamentos de Enfermagem. 5. ${ }^{\mathrm{a}}$ ed. Rio de Janeiro, Intcramerisana, 1977.

4. LOLA, M. ${ }^{a}$ Jurandir de Frsitas - O ambiente da Enfermaria atuando como fator terapêtico: "Uma dimensão da prática da enfermagem". Ri.o de Janeiro, UFRJ, 1980. (Tese Mestre em Enfermagem).

\section{BIBLIOGRA FIA}

1. AZEVEDO, Dulce Oliveira - Aspectos de Humanizaçāo do Serviço de $\bar{x}$ nfermagem no Hospital do Scrvi Jor Público Estadual de São Paulo. Rev. Bras. de Enfermagem D.F. 26(6): 5:5 - 26, 1973.

2. CALDAS, Nal ia Pereira - Ação Supervisora do Administrador de Enfermagem. Roteiro para Estudo. Rio de Janeiro, 1978.

3. .......- Roteiro para Análise Administrativa da Unidade de Internaçāo. Rio de Janeiro, 1980.

4. CANTANHEDE, Cesar - Curso de Organização do Trabalho. 8.a ed. Sāo Paulo, Atlas, 1968.

5. DANIEL, Lilliana Felcher - A Entermagem Planejada. 2. ${ }^{a}$ ed. São Paulo, Cortez \& Morais, 1979.

6. DOURADO, Haydee Guanais - Abordagens Novas na Atençāo de Enîermagem e a Necessidade Comunicaçāo entre os Enfermeiros dos Scrviços e de Ensino. Rev. Bras. de Enfermagem; D.F. 29(1):64-8, 1976

7. DUGAS, de Kozier - Tratado d?Enfermeria Prática, 5. ${ }^{\circledR}$ ed., México, Interamericana, 1974.
5. MIRANDA, Geraldo Inácio - Organizaçāo e Métodos. 2. ${ }^{a}$ ed. S. Paulo, Atlas, 1973.

6. RONCHI, Luciano - Organização, Métodos e Mecanização. 3. ${ }^{\mathrm{a}}$ ed. São Paulo, Atlas, 1968.

7. BRASIL. MINISTERIO DA SAÚDE Normas e Padrōes de Construçāo e Instalaçôes de Serviços de Saúde. Brasilia, 1975.

8. UNIVERSIDADE FEDERAL DO RIO DE JANEIRO - Hospital Universitário. Manual de Prevençāo e Controle de Incêndios. Rio de Janeiro.

\section{CONSULTADA}

8. FELDMANN, Maria Adjutrix - Administraçāo do Serviço de Enfermagem, São Paulo, Centro São Camilo de Desenvolvimento em Administraçāo da Saúde.

9. FINER, Herman - Administraçāo e Serviços de Enfermagem. 1. ad. Sāo Paulo, Livraria Freitas Bastos, 1966.

10. FUERST, Elinor V. et al - Fundamentos de Enfermagem. $5 .^{a}$ ed. Rio de Janeiro, Interamericana, 1977.

11. HORTA, Wanda de Aguiar - Processo de Enfermagem. São Pauı.o, Ed. da Universidade de S. Paulo, 1979.

12. KRON, Thora - Manual de Enfermeria. 4. ed. México, Interamericana, 1977.

13. LÓLA, Maria Jurandir de Frcitas $O$ Ambiente da Enfermaria atıando como fator Terapêtico: "Uma dimensão da prática de enfermagem", Rio de Janeiro, UFRJ/EEAN. 1980 (Tese: Mestre em Enfermagem).

14. MIRANDA, Geraldo Inácio - Organizaçāo e Métodos. 2. ${ }^{\text {a }}$ ed. São Paulo, Atlas, 1973. 
CARNEIRO, A. e Colaboradora - Análise Administrativa sobre Adequaçāo da Area Fisíca. Rev. Bras. Enf.; DF, 34 : 243-259, 1981.

15. NEWMAN, William H. - Açāo administrativa. 4. ${ }^{a}$ ed. São Paulo, Atlas, 1979.

16. RIBEIRO, Maria Augusta Barbosa de C. - Administraçāo de Pessoal nos Hospitais. 2.a ed. São Paulo, Editor Ltda., 1977.

17. RIBEIRO, Circe de Mello - Organizaçāo de Enfermagem. Rev. Bras. Enfermagem; D.F. 26(3) 121:47 1973.

18. RONCHI, Luciano - Organizaçāo, Métodos e Mecanizaçāo. 5. ${ }^{\text {a }}$ ed. Sāo Paulo, Atlas, 1968.

19. SCARES, Enedina - Unidade de I:mergência - Estrutura e Equipa- mento. Rio de Janeiro, UFF Departamento de Enfermagem, 1975. (Tese - Livre Docente).

20. SOCIEDADE BENEFICENTE SÃO CAMILO - Chefia em Hospitais. São Paulo, CEBRAE, 1976.

21. UNIVERSIDADE FEDERAL DO RIO DE JANEIRO - Hospital Universitário. Manual de Prevençāo e Controle de Incêndios, Rio de Janeiro.

22. BRASIL - MINIST:SRIO DA SAÚDE - Normas e Padrōes de Construçōes e Instalaçōes de Serviços de Saúde. Brasília, 1979. 